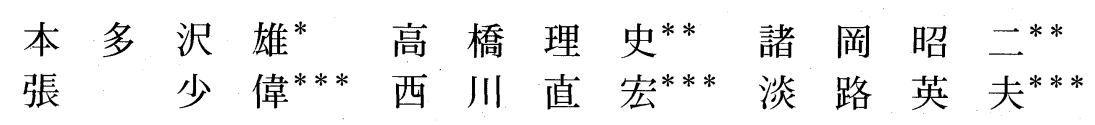

\title{
Thermal Stress and Stress Intensity Factor Considering Temperature Dependent Material Properties - A Circular Disk under Constant Heat Flux -
}

\author{
by
Sawao Honda ${ }^{*}$, Toshifumi Takahashi ${ }^{*}$, Syouji MorookA ${ }^{* *}$, Shaowei Zhang $^{* * *}$, Tadahiro NishiKawa ${ }^{* * *}$ and Hideo AwAII **

\begin{abstract}
An infrared radiation heating method was proposed previously as a new technique for estimating thermal shock parameters directly from electrical power charge. The method uses a thin-circular disk heated by infrared rays at the central area with a constant heat flux. In this report, temperature and stress distributions in the disk are analyzed numerically considering the temperature-dependent material properties of alumina and float glass, namely, temperature-dependent thermal conductivity and thermal diffusivity for the temperature distribution and temperature-dependent thermal expansion for the stress distribution. Furthermore, stress intensity factors are analyzed for a disk with an edge crack subjected to a constant heat flux. These results show that the temperature dependence of material properties has siginificant effects on the temperature and stress distributions.
\end{abstract}

Key words : Temperature distribution, Thermal stress, Stress intensity factor, Temperature-dependent material properties, Thermal shock testing, Constant heat flux

\section{1 緒言}

多結晶セラミックスは耐熱性に優れた構造材料として その用途拡大が見込まれているが，一般にセラミックス は常温において極めてぜい性的に振る舞うのみならず, 高温においても粒界層の軟化により擬ぜい性的破壊挙動 を示す材料である。また，熱衝撃破壊は温度差を急激に うけるときに生じる熱応力による破壊であり，七ラミッ クスは高温で使用される機会の多いことから熱衝撃環境 にさらされやすい材料といえる．従って，七ラミックス の熱衝撃破壊特性を定量的に明らかにすることは，七ラ ミックスの耐熱性材料としての信頼性を向上する上で重 要である。

材料の熱衝撃特性を評価する方法として, 従来より水 中急冷法, ${ }^{1}$ 抵抗加熱法, ${ }^{2)}$ レーザ加熱法, ${ }^{3)}$ ガ ス加熱法, ${ }^{4)} \mathcal{P}$ 一ク放電加熱法) などいくつかの試験法が提案されてい るが，その多くは熱衝撃破壞特性を定性的に評価するも のである，中でも，水中急冷法は簡便であることから $\mathrm{JIS}^{6)}$ にも規定されているが, 温度差が $220^{\circ} \mathrm{C}$ 以上のとき の水の沸騰領域における熱伝達係数の大幅な変動は, 熱 衝撃破壊特性に極めて顕著な影響を与えることが知られ ており, また , 熱衝撃パラメータとして得られる臨界温 度差はビオ数に強く依存するという問題がある。ささらに，
材料表面の変質や粒界層の軟化を伴うような高温域から の水中急冷は, 熱衝撃抵抗特性を正しく評価することは 難しくなるため避けるべきであり，このようなことから 考元ると, 水中急冷法の有効な温度範囲は, 実際上極め て限定されたものとなる.

筆者らは最近, 熱衝撃破壞特性を定量的に評価する ことを目的として, 赤外線放射加熱法を提案してい $3^{8 .}{ }^{8)}$ (10) この方法は, 赤外線放射により薄い円板の中央 部を一定熱流束で加熱するというものであり，熱衝撃強 度，熱衝撃破壊じん性を熱負荷より直接に測定でき，か つ,これらの熱衝撃パラメータを物性值として評価する ことが可能である. 熱衝撃試験に用いられる電磁波には 赤外線の他にレーザがあるが，レーザ加熱では動的熱応 力が発生するといわれている. ${ }^{11)}$ それに対し，赤外線加熱 はレーザほどには急激な加熱ではなく，動的熱応力の効 果は無視できる。ささらに, 赤外線は構造材料の使用温度 範囲内では最も高い熱放射を有し, 物体の急速加熱等に 広く用いられている。 また, 入力電力の制御により熱流 束一定加熱が容易に行える．このようなことから，赤外 線放射加熱法はセラミックスの熱衝撃破壊特性を定量的 に評価する方法として有効であるといえる.

赤外線放射加熱試験に用いられる円板試験片の熱応力

原稿受理 平成 9 年 1 月 27 日 Received Jan. 27, 1997

* 科学技術振興事業団セラミックス超塑性プロジェクト $=456$ 名古屋市熱田区六野, JST, Atsuta-ku, Nagoya, 456

$* *$ 名古屋工業大学材料工学科 T466 名古屋市昭和区御器所町, Dept. of Mat. Sci. \& Engng., Nagoya Inst. Tech., Showa-ku, Nagoya, 466

$* * *$ 正会員 名古屋工業大学材料工学科 T466 名古屋市昭和区御器所町, Dept. of Mat. Sci. \& Engng., Nagoya Inst. Tech., Showa-ku, Nagoya, 466 


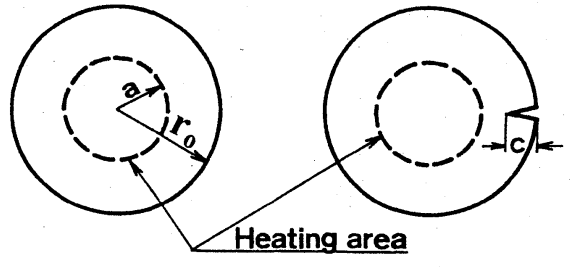

(a)

(b)

Fig. 1. Thin circular, disk-shaped specimens (a) without crack, and (b) with edge crack.

解析，および，縁き裂のある円板の中心部を急速加熱す るときの応力拡大係数の解析は, 熱物性の温度依存を考 慮しない場合については以前に報告しているが ${ }^{12), 13)}$ こでは, 熱衝撃破壞に関与する熱物性が温度依存を有す る場合についての解析を目的とする。熱物性の温度依存 性を考慮することにより，熱伝導方程式は非線形となり 解析は一般に困難となるが，ここでは温度分布の解析に 関しては高津らの方法 ${ }^{14)}$ に従い, 熱伝導率, 熱拡散率の 温度依存を考虑した数值解析を行う. また, 熱応力につ いては非連成問題と考えて, 解析された温度分布を用い, かつ, 線膨張係数の温度依存性を考慮した解析を行う。 また, 縁き裂のある円板の応力拡大係数は, 解析された き裂面上の熱応力分布から以前に報告した方法 ${ }^{8}$ を用い て計算する。

\section{2 解 析}

\section{$2 \cdot 1$ 熱伝導方程式}

まず，半径 $r_{0}$ の薄い円板の中央部に一定の熱流束 (単位時間, 単位面積あたりの熱量) を与えるときの温度 分布を解析する.ここで，Fig. 1 (a) に示すような一定 熱流束加熱の問題を，円板の中央部で一定発熱のある問 題と考えると, 円板内の温度分布は, 次のような物性値 を温度の関数とする 1 次元熱伝導方程式の解として与え られる. ${ }^{15)}$

$$
\rho c \frac{\partial \theta}{\partial t}=\frac{1}{r} \frac{\partial}{\partial r}\left(\lambda r \frac{\partial \theta}{\partial r}\right)+w
$$

ここに, $\rho$ : 密度, $c$ : 比熱, $\theta$ : 温度, $t$ : 時間, $r$ : 極座標に扔ける半径座標, $\lambda$ : 熱伝導率である. ま た, $w$ は単位時間, 単位体積あたりの発熱量であり次の ようにとる。

$$
\begin{array}{ll}
w=w & 0 \leq r \leq a \\
w=0 & a<r \leq r_{0}
\end{array}
$$

$\alpha$ は加熱部の半径である. 式 (1) を初期条件,

$$
t=0 \quad \theta=\theta_{i}
$$

境界条件，

$$
\begin{array}{ll}
r=r_{0} & \frac{\partial \theta}{\partial r}=0 \\
r=0 & \frac{\partial \theta}{\partial r}=0
\end{array}
$$

のもとで解く。 $\theta_{i}$ は円板の初期温度であり, 一定と する。
発熱量 $w$ と赤外線放射加熱による熱流束 $q$ との関係は 次のように表される. 赤外線加熱装置の電力値を $W$, その熱効率を $\eta$ とすると, 円板に供給される熱流束 $q$ は, 定常状態で,

$$
q=\frac{\eta W}{\pi a^{2}}
$$

となる. よって，円板の板厚を $H$ とすると，

$$
w=\frac{q}{H}
$$

という関係が得られる。

熱伝導方程式 (1) の解析を行うために, 次のような無 次元変数を用いる.

$$
\begin{aligned}
& \xi=\frac{r}{r_{0}}, T=\frac{\theta-\theta_{i}}{Q}, Q=\frac{q r_{0}^{2}}{\lambda_{i} H}, \tau=\frac{\kappa_{i} t}{r_{0}^{2}}, \\
& \kappa^{*}=\frac{\kappa}{\kappa_{i}}, \lambda^{*}=\frac{\lambda}{\lambda_{i}},(\rho c)^{*}=\frac{\rho c}{(\rho c)_{i}}
\end{aligned}
$$

ここに, $\xi$ : 無次元座標, $T$ : 無次元温度, $\tau:$ 無次 元時間, $\kappa$ : 熱拡散率である. 物性値に下付き添え字 $i$ のつくものは初期温度における值, 上付き添え字*のつ くものは無次元物性值を表す．また， $Q$ は温度を無次元 化するためのものであり, 同時に無次元発熱量 $w$ を単位 化する. 物性値は初期温度に打ける值で無次元化してお

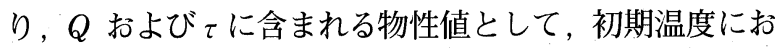
ける値を用いていることに注意されたい．

式 (1) にこれらの無次元変数を用いると，

$$
(\rho c)^{*} \frac{\partial T}{\partial \tau}=\frac{1}{\xi} \frac{\partial}{\partial \xi}\left(\lambda^{*} \xi \frac{\partial T}{\partial \xi}\right)+W
$$

のように表され，発熱条件は

$$
W=\frac{w}{q} H=1\left(0 \leq \xi \leq a / r_{0}\right)
$$

となる。式 (8) は非線形偏微分方程式であり，このまま では解析が困難であるので，よく知られた次のような変 数変換を行う. ${ }^{16)}$

$$
G=\int_{0}^{T} \lambda^{*} d T
$$

その結果，式 (8) は次のように表される。

$$
\frac{1}{\kappa^{*}} \frac{\partial G}{\partial \tau}=\frac{\partial^{2} G}{\partial \xi^{2}}+\frac{1}{\xi} \frac{\partial G}{\partial \xi}+W
$$

初期条件は，

$$
\tau=0 \quad G=0
$$

境界条件は，

$$
\begin{array}{ll}
\xi=0 & \frac{\partial G}{\partial \xi}=0 \\
\xi=1 & \frac{\partial G}{\partial \xi}=0
\end{array}
$$

発熱条件は，

$$
\begin{array}{ll}
a / r_{0}<\xi \leq 1 & W=0 \\
0 \leq \xi \leq a / r_{0} & W=1
\end{array}
$$

となる. 式 (11) にクランク・ニコルソンの差分表示 ${ }^{177}$ を 用いると，次のような差分方程式が得られる. 
Table I . Mechanical properties of alumina.

\begin{tabular}{|c|c|c|c|c|}
\hline \multirow[t]{2}{*}{$\therefore$} & \multicolumn{3}{|c|}{ Temperature, $\theta\left[{ }^{\circ} \mathrm{C}\right]$} & \multirow[b]{2}{*}{800} \\
\hline & 25 & 300 & 500 & \\
\hline $\begin{array}{l}\text { Density } \\
\qquad \rho\left[\mathrm{kg} / \mathrm{m}^{3}\right]\end{array}$ & $3.80 \mathrm{E} 3$ & & & \\
\hline $\begin{array}{l}\text { Young's modulus } \\
\text { E[GPa] }\end{array}$ & 359 & 348 & 340 & 325 \\
\hline $\begin{array}{l}\text { Specific heat } \\
\mathrm{c}[\mathrm{J} / \mathrm{kgK}]\end{array}$ & $7.90 \mathrm{E} 2$ & $1.07 \mathrm{E} 3$ & $1.17 \mathrm{E} 3$ & $1.26 \mathrm{E} 3$ \\
\hline $\begin{array}{l}\text { Thermal diffusivity } \\
\kappa\left[\mathrm{m}^{2} / \mathrm{s}\right]\end{array}$ & $1.10 \mathrm{E}-5$ & $3.69 \mathrm{E}-6$ & $2.70 \mathrm{E}-6$ & $1.90 \mathrm{E}-6$ \\
\hline $\begin{array}{l}\text { Thermal conductivity } \\
\lambda[\mathrm{W} / \mathrm{mK}]\end{array}$ & 33.0 & 15.0 & 12.0 & 9.1 \\
\hline $\begin{array}{l}\text { Linear thermal } \\
\text { expansion } \alpha[1 / \mathrm{K}]\end{array}$ & $6.9 \mathrm{E}-6^{1)}$ & $\left.7.9 \mathrm{E}-6^{2}\right)$ & $8.2 \mathrm{E}-6^{3)}$ & \\
\hline
\end{tabular}

Table II. Mechanical properties of float glass.

$$
\text { Temperature, } \theta\left[{ }^{\circ} \mathrm{C}\right]
$$

\begin{tabular}{|c|c|c|c|c|}
\hline \\
\hline & 25 & 200 & 400 & 500 \\
\hline $\begin{array}{l}\text { Density } \\
\qquad \rho\left[\mathrm{kg} / \mathrm{m}^{3}\right]\end{array}$ & $2.43 \mathrm{E} 3$ & & & \\
\hline $\begin{array}{l}\text { Young's modulus } \\
\text { E[GPa] }\end{array}$ & 72.9 & 71.1 & 69.1 & 68.0 \\
\hline $\begin{array}{l}\text { Specific heat } \\
\mathrm{c}[\mathrm{J} / \mathrm{kgK}]\end{array}$ & $8.28 \mathrm{E} 2$ & $1.01 \mathrm{E} 3$ & $1.16 \mathrm{E} 3$ & \\
\hline $\begin{array}{l}\text { Thermal diffusivity } \\
\kappa\left[\mathrm{m}^{2} / \mathrm{s}\right]\end{array}$ & $5.29 \mathrm{E}-7$ & $5.00 \mathrm{E}-7$ & $4.91 \mathrm{E}-7$ & \\
\hline $\begin{array}{l}\text { Thermal conductivity } \\
\lambda[\mathrm{W} / \mathrm{mK}]\end{array}$ & 1.06 & 1.23 & 1.38 & \\
\hline $\begin{array}{l}\text { Linear thermal } \\
\text { expansion } \alpha[1 / \mathrm{K}]\end{array}$ & $9.0 \mathrm{E}-6^{1)}$ & $9.1 \mathrm{E}-6^{2}$ & $9.3 \mathrm{E}-6^{3)}$ & $9.4 \mathrm{E}-6^{4)}$ \\
\hline
\end{tabular}

$-\kappa^{\star}\left(\frac{N_{1}}{2}+N_{2}\right) G_{m+1, n+1}+\left(\kappa^{\star} N_{1}+1\right) G_{m, n+1}$

$-\kappa^{\star}\left(\frac{N_{1}}{2}-N_{2}\right) G_{m-1, n+1}$

$=\kappa^{\star}\left(\frac{N_{1}}{2}+N_{2}\right) G_{m+1, n}-\left(\kappa^{\star} N_{1}-1\right) G_{m, n}$

$+\kappa^{*}\left(\frac{N_{1}}{2}-N_{2}\right) G_{m-1, n}+\Delta \eta W$

ここに, 時刻を $\tau=n \Delta \tau(n=1,2, \ldots N)$, 座標を $\xi=$ $m \Delta \xi(m=1,2, \ldots M)$ と差分表示し，

$$
N_{1}=\frac{\Delta \tau}{\Delta \xi^{2}}, \quad N_{2}=\frac{\Delta \tau}{4 \xi \Delta \xi}
$$

と打いた. 式 (15) に初期条件, 境界条件を用いて連立 一次方程式を作り, 数值計算することにより $G$ が得ら れる.

\section{$2 \cdot 2$ 熱物性の関数近似}

熱衝撃破壊に関与する物性值には, 熱伝導率 $\lambda$, 熱拡 散率 $\kappa$, 比熱 $c$, 密度 $\rho$, 線膨張係数 $\alpha$, ヤング率 $E$, 引張強度 $\sigma_{c}$, 破壊じん性 $K_{\text {IC }}$ があり, これらの多くは 温度依存性を示す. 例えば Fig. 2 と Fig. 3 はそれ艺れ Table I と Table II に示したアルミナと板ガラスの熱伝導 率, 熱拡散率, 線膨張係数とヤング率の值を室温の值を 基準に無次元化し，その温度依存性を示したものである. これより，これらの材料の物性值の温度依存はかなり異 なった傾向を示すこと，および，熱伝導率や熱拡散率は 室温付近での温度依存性が大きく, 熱衝撃破壊問題を解
析する場合には，材料の物性の温度依存を考慮する必要 のあることが理解される. なお, ヤング率, 引張強度と 破壊じん性については，もともと熱衝撃試験を行う温度 範囲内ではその温度依存性は小さいこと，ここでの熱衝 撃試験をできるだけ温度差の小さい範囲で行うようにし ていることから，それらの温度依存性を無視して扱う。

式 (15) の数值解析を容易にするため, 無次元熱伝導率 $\lambda^{*}$, 無次元熱拡散率 $\kappa$ *を次のように 2 次式で近似する.

$$
\begin{aligned}
& \lambda^{*}=1+c_{1} T+c_{2} T^{2} \\
& \kappa^{*}=1+c_{3} T+c_{4} T^{2}
\end{aligned}
$$

Nishikawa らは近似式として指数関数 ${ }^{18)}$ と 1 次式 ${ }^{19)}$ を 用いており，それは式 (10) の逆変換である $G$ から $T$ へ の変換が容易に行われ，かつ，境界条件の表示が簡単に なるためであった。 しかし，ここで考えている問題では， これらの物性值は境界条件に関与しないので，より厳密 な関数近似が可能となる 2 次式を用いた， $G$ から $T$ への 逆変換は, 式 (10) へ式 (17) を代入することにより,

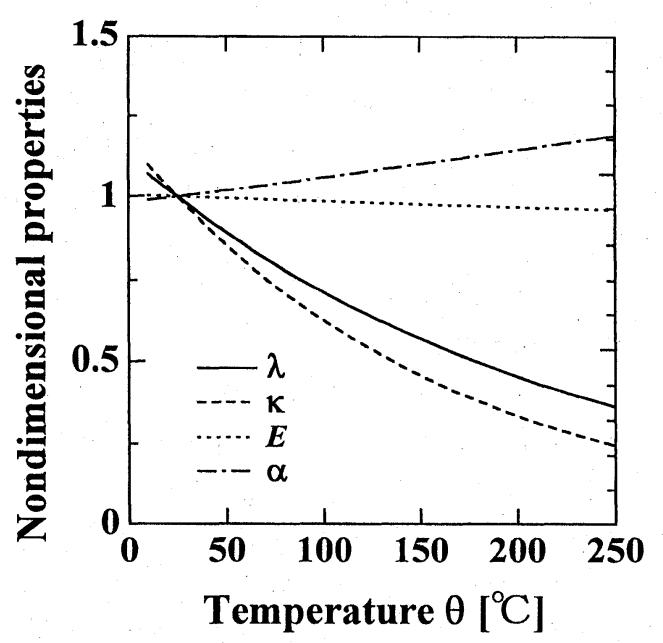

Fig. 2. Relationship between thermal properties of alumina and temperature.

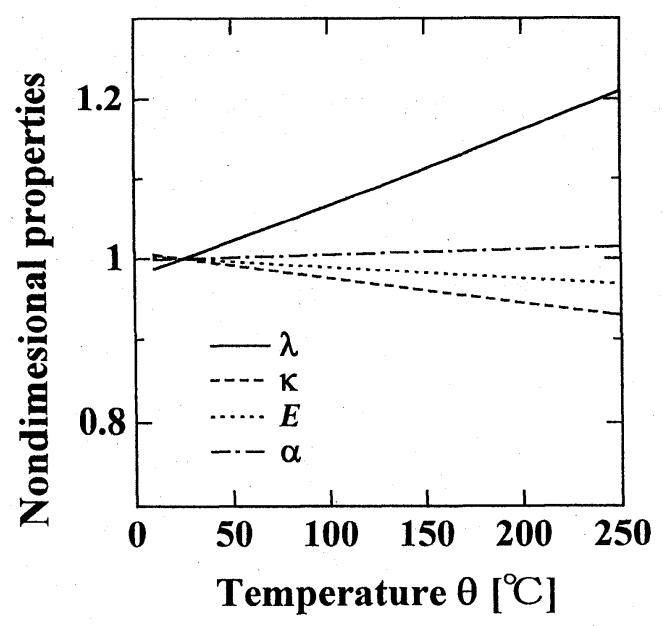

Fig. 3. Relationship between thermal properties of float glass and temperature. 


$$
G=T+\frac{c_{1}}{2} T^{2}+\frac{c_{2}}{3} T^{3}
$$

が得られるので, 数值計算された $G$ の值からニュートン 法により $T$ を求める.

\section{$2 \cdot 3$ 熱応力の解析}

線膨張係数のみの温度依存を考慮するときの，薄い円 板の軸対称問題に関する熱応力は，非連成問題と考えて 文献 $^{20)}$ より次のように求められる.

$$
\sigma_{\theta}=E\left\{\frac{1}{\gamma_{0}^{2}} \int_{0}^{r_{0}} \alpha \theta r d r+\frac{1}{r^{2}} \int_{0}^{r} \alpha \theta r d r-\alpha \theta\right\}
$$

ここでは円周応力のみを表示した. 上式に，熱伝導方 程式と同様な無次元化を行うと, 次のような無次元応力 が得られる。

$$
\frac{\sigma_{\theta}}{E_{i} \alpha_{i} Q}=\int_{0}^{1} \alpha^{*}\left(T+\frac{\theta_{i}}{Q}\right) \xi d \xi+\frac{1}{\xi^{2}} \int_{0}^{\xi} \alpha^{*}\left(T+\frac{\theta_{i}}{Q}\right) \xi d \xi-\alpha^{*}\left(T+\frac{\theta_{i}}{Q}\right)
$$

ここに無次元線膨張係数 $\alpha$ *の定義は,

$$
\alpha^{*}=\frac{\alpha}{\alpha_{i}}
$$

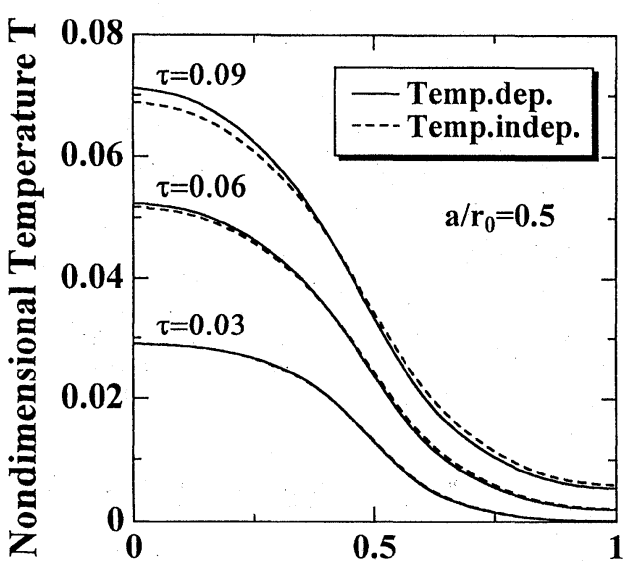

Nondimensional Distance $\xi$

Fig. 4. Nondimensional temperature distribution in a disk of alumina.

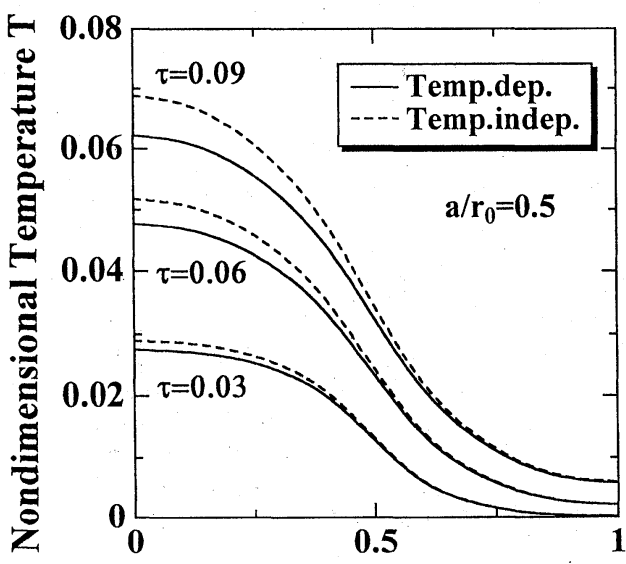

Nondimensional Distance $\xi$

Fig. 5. Nondimensional temperature distribution in a disk of float glass.
としている。また，ヤング率の温度依存を考えていない ので, $E=E_{\mathrm{i}}$ である. $\alpha^{*}$ を多項式近似し，式 (20) に前 節で解析された温度分布を代入して数值積分すると, 熱 物性の温度依存を考慮したときの熱応力が計算される。

\section{$2 \cdot 4$ 応力拡大係数}

Fig. 1 (b) に示すような, 縁き裂のある円板の中央に 一定熱流束を与えるときの応力拡大係数を解析する．こ こで無次元応力拡大係数 $N_{I}$ は次のように定義する.

$$
K_{I}=N_{I} \sqrt{\pi c} E_{i} \alpha_{i} Q
$$

$K_{I}$ : 応力拡大係数, $c$ ：縁き裂長さである. 応力拡大 係数はき裂面上に働く熱応力から計算されるが，その解 析方法は以前に報告してある ${ }^{8)}$ ので省略する。

\section{3 数値解析結果}

\section{$3 \cdot 1$ 温度分布}

物性值の温度依存性の大きく異なるアルミナと板ガラ スについて解析した結果を示す。アルミナは多結晶 $99 \%$ アルミナ（京セラ，A479），板ガラスは市販の空ガラス 用ソーダ石灰ガラスである。それらの物性值を Table I と Table IIに示す．これらの值は，アルミナについては カタログ值を用い，板ガラスについては，ヤング率は曲 げ共振法，比熱，熱拡散率，熱伝導率はレーザフラッシ ユ法, 線膨張係数は示差式熱膨張計による測定值であ る.

まず温度分布についての解析結果を示す。温度分布の 差分法解析において，時間は 100 分割，距離は 300 分割 として計算した. 2 つの材料について, 温度依存性を考 慮する場合と考慮しない場合の, 円板の半径方向の無次 元温度分布をそれぞれ Fig. 4 と Fig. 5 に示す。縦軸は無 次元温度, 横軸は円板の中心を原点とする無次元距離で あり，パラメータとして無次元時間をとった。図中，実 線は温度依存を考えた場合，破線は温度依存を考えない 場合である。困より，発熱時間が長くなるほど，または， 温度が上昇するほど熱物性の温度依存が顕著になること がわかる.

\section{$3 \cdot 2$ 熱応力分布}

Fig. 4, Fig. 5 の温度分布を式 (20) に代入し，線膨張係 数の温度依存を考慮した場合と考慮しない場合の熱応力 を解析した。積分はシンプソン則によった。アルミナと 板ガラスについての無次元円周応力の解析結果をそれぞ れ Fig. 6 と Fig. 7 に示す. 縦軸は無次元円周応力である. この場合も加熱時間が長くなるほど熱物性の温度依存が 現れ，特に最大熱応力の值の温度依存が大きいことがわ かる．また，最大熱応力の発生する位置も若干変化する のが認められる。

\section{$3 \cdot 3$ 応力拡大係数}

縁き裂のある円板に一定熱流束を与えるときの無次元 応力拡大係数を，アルミナと板ガラスについてそれぞれ Fig. 8 と Fig. 9 に示す.ここに, 縦軸は無次元応力拡大 係数, 横軸は無次元時間であり, 加熱半径比 $a / r_{o}$ をパ ラメータとして，き裂長さ比 $c / r_{0}=0.1$ の場合のみの結果 を示した，物性值の温度依存を考慮しない破線の場合に 
は, 無次元時間が 0.5 以上では熱応力が収束するのに伴 い $N_{I}$ も収束するが, 温度依存を考慮する場合には $\tau>$ 0.5 においても $N_{I}$ は一定值に収束することはなく, ま た，アルミナと板ガラスとではその挙動が大きく異なる のがわかる. 即ち, アルミナに扔ては Fig. 6 に示すよ うに, 円周熱応力の最大值は温度依存性を考光ないとき よりもかなり大きくなるため, Fig. 8 の応力拡大係数は 時間経過とともに増大する。一方, 板ガラスの熱応力の 温度依存性は小さく, かつ, 温度依存を考慮する方が考

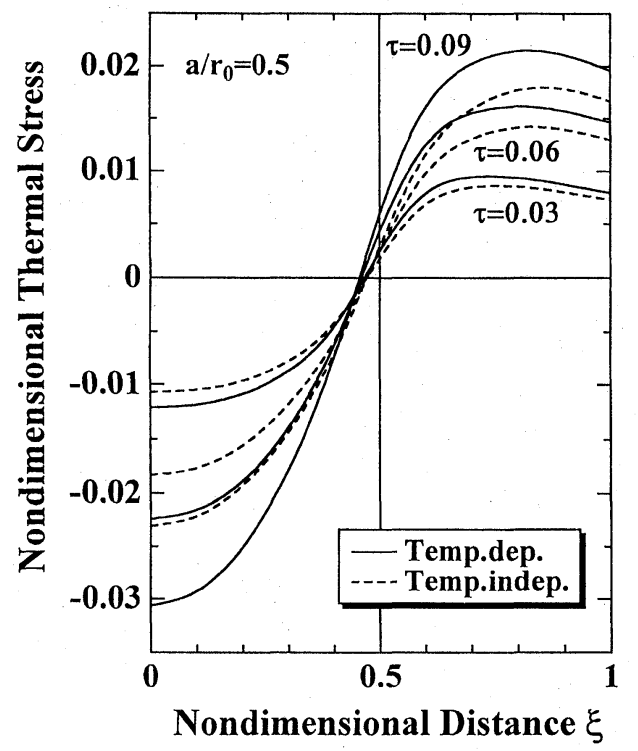

Fig. 6. Nondimensional thermal stress distribution in a disk of alumina.

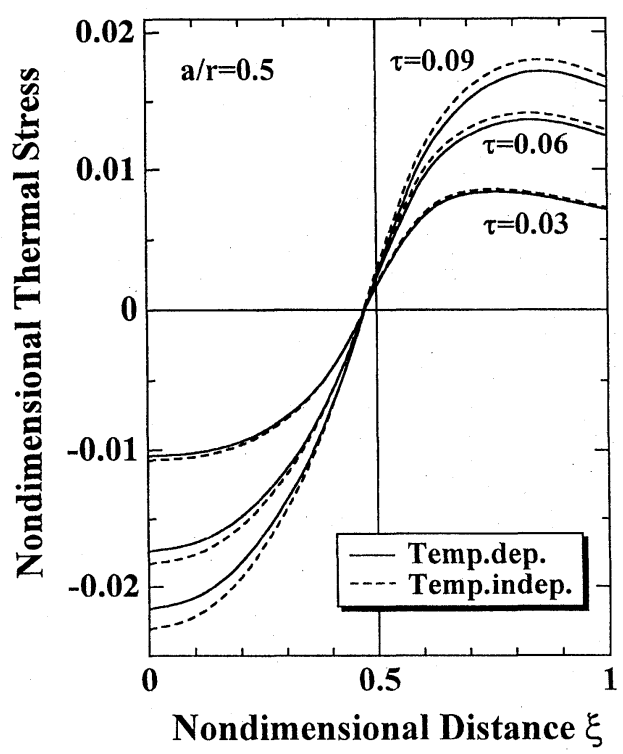

Fig. 7. Nondimensional thermal stress distribution in a disk of float glass.
慮しない場合よりも小さくなるため, 応力拡大係数は $\tau$ が 0.3 以上で低下する.

\section{4 結論}

一定熱流束をうける円板について, 物性值の温度依存 を考慮したときの温度, 熱応力, 応力拡大係数の解析を 行った。解析に用いた試料は, 物性值の温度依存性の大 きく異なるアルミナと板ガラスである。まず，温度分布 については熱伝導率, 熱拡散率を 2 次式で近似し, クラ ンク・ニコルソン表示による差分法を用いて解析した。 次に, 熱応力分布については解析された温度分布を用い, かつ, 線膨張係数の温度依存を考慮して数值解析した。 さらに, 縁き裂のある円板の応力拡大係数については, 物性の温度依存を考慮して解析されたき裂面上の熱応力 から計算した。 その結果, 物性值の温度依存性は温度分 布, 熱応力分布, 応力拡大係数のすべてに扔いて無視で

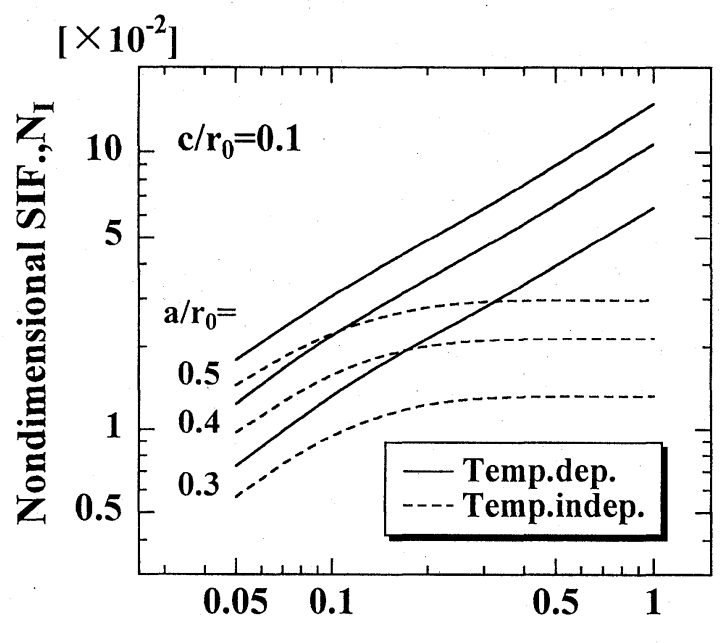

Nondimensional Time $\tau$

Fig. 8. Nondimensional stress intensity factor of a disk with an edge crack. The material is alumina.

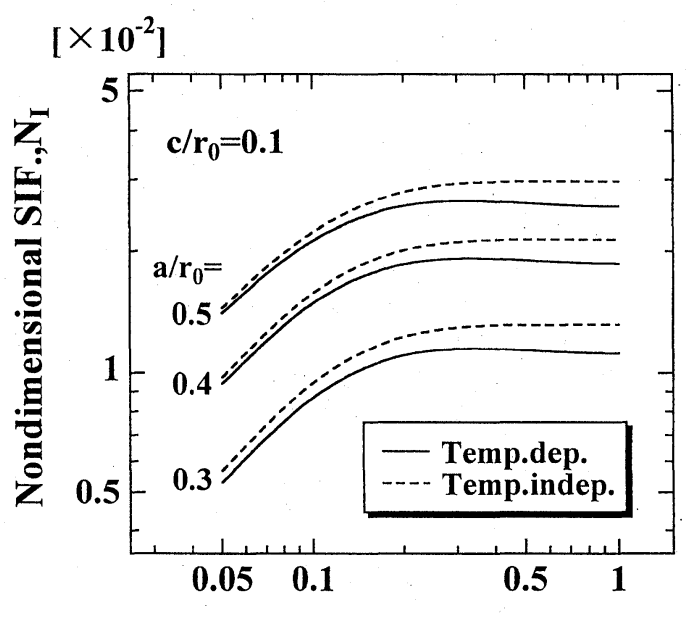

Nondimensional Time $\tau$

Fig. 9. Nondimensional stress intensity factor of a disk with an edge crack. The material is float glass. 
きないことが示された.

本研究は平成 7 年度大倉和親記念財団の研究助成に よりなされたものである。記して謝意を表する。

\section{参 考 文 献}

1）佐久間俊雄, 岩田宇一, 高久 啓, 日本機械学会論文集, A-57, 2741 (1991).

2 ) 水谷安伸, 西川直宏, 福井隆光, 高津 學, J. Ceram, Soc. Japan, 103, 494 (1995).

3 ) 橋田俊之, 若菜健司, 高橋秀明, 日本機械学会論文集, A56, 1952 (1990).

4) 川崎 亮, 日比野 敦, 渡辺龍三, 日本金属学会誌, 56, 472 (1992)

5 ) S. Sato, H. Awaji, Y. Imamura, K. Kawamata and T. Oku, "Thernal Stresses in Severe Environments", Ed. by D. P. H. Hasselman and R. A. Heller, P.535 (1980) Plenum Press.

6) JIS R1615-1993.

7）高鐵, 西川直宏, 日比雅義, 高津 學, J. Ceram. Soc. Japan, 101, 788 (1993).

8）淡路英夫，日本機械学会論文集，A-62，700（1996).

9）淡路英夫, 遠藤智義, J. Ceram. Soc. Japan, 103, 960
(1995).

10) H. Awaji and T. Endo, Proc. 4th Japan Int. SAMPE Symp., p.335 (1995).

11) D. W. Tang, B. L. Zhou, H. Cao and G. H. He, Appl. Phys. Lett., 59, 3113 (1991).

12）淡路英夫, 佐藤千之助，日本材料強度学会誌， 13, 78 (1978).

13) S. Sato, H. Awaji, K. Kawamata and J. Kon, Proc. 21 Japan Congr. Mater. Res., p.64 (1979) JSMS.

14) 高津 學, 西川直宏, 水谷安伸, 化学工学論文集, $\mathbf{1 9}$, 633 (1993).

15）庄司正弘, “伝熱工学”, p. 53 （1995）東京大学出版会.

16）甲藤好郎，“伝熱概論”, p. 434（1964）養賢堂.

17）庄司正弘, “伝熱工学”, p. 111 （1995）東京大学出版会.

18) T. Nishikawa, T. Mizui, M. Takatsu and Y. Mizutani, J. Mater. Sci., 30, 5013 (1995).

19）西川直宏, 水谷安伸, 本多沢雄, 高津 學, J.Ceram. Soc. Japan, 103, 923 (1995)

20) S. P. Timoshenko and J. N. Goodier, "Theory of elasticity", 3rd ed., p.441 (1970) McGraw-Hill. 